\title{
Measuring Productivity of Citrus Hand Harvesters and Assessing Implications on Harvest Costs and Mechanical Harvesting Developments ${ }^{1}$
}

\author{
Fritz M. Roka and Barbara R. Hyman²
}

\section{Introduction}

Canopy shakers (Figure 1) are used in Florida to harvest sweet oranges for processed juice. These mechanical systems recover 70 to 95 percent of the crop. The wide range in fruit recovery accounts for factors such as time of year, the pull-force required to separate fruit from the trees, size of the trees, uniformity of the tree canopy, and whether the mechanical harvesting equipment is designed to fit the shape of the trees. Given that less than 100 percent of the crop will be recovered by a mechanical harvester, an important question becomes whether a grower should "glean" behind a mechanical harvesting system. Gleaning is done with manual labor, and collects any marketable fruit that a mechanical harvester leaves behind. The simple answer to a grower's "gleaning" question is that gleaning should occur so long as the market value of a gleaned box is greater than the unit costs to harvest and haul that box to a processing plant. What complicates this question is that a functional relationship exists between worker productivity and the volume of fruit available to be hand harvested or gleaned. Fruit harvesters and employers of fruit harvesters have observed that average worker productivity, or number of boxes harvested per hour, increases (decreases) with higher (lower) crop yields. Quantitatively, however, this relationship has yet to be measured. If a worker's productivity is, in fact, adversely affected by crop yield, to what extent should piece rates increase to maintain worker hourly earnings and/or meet minimum wage levels? As mechanical
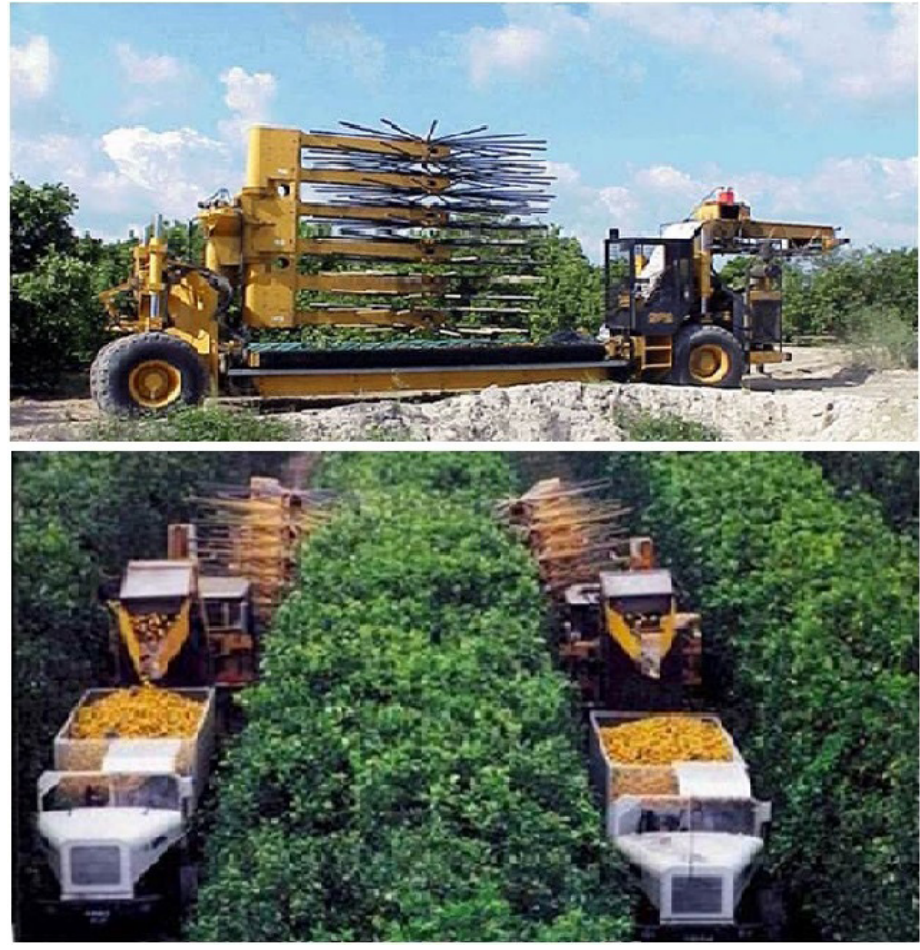

Figure 1. Continuous canopy shake and catch citrus mechanical harvesting system.

harvesting systems improve and fruit recovery percentages increase, less available fruit will remain, and thus a higher piece rate may be required to pay for gleaning services. Quantifying the relationship between available fruit and worker productivity should help determine economic thresholds over which gleaning should occur.

1. This is EDIS document FE933, a publication of the Food and Resource Economics Department, Florida Cooperative Extension Service, Institute of Food and Agricultural Sciences, University of Florida, Gainesville, FL. Published May 2013. Please visit the EDIS website at http://edis.ifas.ufl.edu.

2. Fritz M. Roka, associate professor, Food and Resource Economics Department, and Barbara R. Hyman, educational coordinator, UF/IFAS Citrus Mechanical Harvesting and Abscission Program, University of Florida, Southwest Florida Research and Education Center, Immokalee, FL 


\section{Harvesting Citrus in Florida - Hand and Mechanical}

Hand harvesting of citrus includes two charges: pick and roadside. The pick, or piece rate, is the amount paid to workers for each box $(90 \mathrm{lb})$ they harvest. A worker's hourly earnings are calculated by multiplying the piece rate by his/ her individual productivity (number of boxes harvested per hour). If a worker spends 8 hours harvesting and collects 80 boxes of fruit during the course of the day, then his/ her average productivity is 10 boxes per hour. If the same worker is paid a piece rate of 90 cents per box, then his/her total earnings for the day would be $\$ 72$ (at $\$ 9$ per hour). Roadside is a separate charge that goes to the harvesting company and covers ownership costs of harvesting equipment, worker payroll taxes, workers' compensation insurance, salaries of field foremen or crew leaders, and profit to the harvesting company. Roadside charges increase with pick rates, but not on a one-to-one basis. Together, the pick and roadside costs in Florida account for nearly 25 percent of the total cost to grow and deliver citrus fruit to a juice processing facility (Muraro 2009).

A continuous canopy-shake and catch system (CCSC, Figure 1) replaces the pick and roadside functions of a hand-harvesting crew. The system includes two harvesters, one working on each side of a tree row, and four field trunks that collect and transport the fruit to the bulk fruit trailers at the edge of a grove. The harvesters have large tines mounted on a 16-foot-tall wheel-like apparatus called a "whirl." These tines rake through the tree canopy and drop fruit onto a catch frame, which in turn conveys fruit to a field truck moving behind the harvester. The harvesters travel at speeds between 1 and 2 miles per hour (mph) down a tree row, and can harvest 300 trees an hour. Field data describing equipment performance and records from harvesting companies indicate that CCSC systems remove and deliver to the bulk trailers between 75 and 93 percent of the fruit hanging on a tree prior to harvest (Roka and Hyman 2004). For further information on CCSC systems, including photos and videos, visit the University of Florida's citrus mechanical website at http://citrusMH.ifas.ufl.edu.

A long-term engineering goal is to improve fruit recovery percentages of CCSC equipment. Even with improvements to catch-frame design and fruit removal technology, mechanical harvesting equipment will not likely recover 100 percent of the available fruit from a tree. Therefore, growers who use mechanical harvesting systems will face the gleaning question with every block they harvest with mechanical systems.
Minimum wage rates and worker earning expectations require employers to track hourly earnings. In most cases, experienced citrus harvesters earn more than the minimum wage (in January 2013, Florida minimum wage was $\$ 7.79$ / hour). Therefore, to entice workers to shift from handpicking to gleaning after a mechanical system, workers must be assured that their expected hourly earnings will remain at least the same. If worker productivity is adversely affected by limited fruit availability per tree or acre, then the workers expect an increase in piece rates to maintain a target level of hourly earnings. Before a reasonable piece rate can be established, there needs to be a way of predicting the extent to which worker productivity under gleaning conditions would change relative to full-harvest conditions.

\section{A Model for Labor Productivity}

A study was conducted during the 2008-09 season to determine the extent to which fruit yield volumes affect fruit harvesters' average productivity. Yield data were collected from 112 citrus blocks that were harvested in southwest Florida between November 27, 2007 and June 1,2008 . Blocks ranged in size from 16 to 151 acres and included early/midseason varieties (Hamlin, Parson Brown, and Pineapple) as well as late season varieties (Valencia and Rohde Red Valencia). On 38 blocks, the oranges were harvested completely by hand. On the remaining 74 blocks, a mechanical system (CCSC, Oxbo International Corporation) initially harvested the block, and then any remaining fruit were gleaned by a hand crew. The yield data from machines were separated from what was harvested by gleaning crews. The study was unable to control for differences in productivity among individual workers because gleaning crews are organized separately from full-harvest crews. The worker productivity data reported from this study reflect average productivity across the entire crew for the days that harvest data were collected.

Table 1 summarizes the yield and worker productivity data from this study. While blocks that were mechanically harvested averaged higher yields than blocks that were hand harvested, the production differences were not statistically significant. Interestingly, grower perceptions about the adverse effects from mechanical harvesters on tree health and crop yield would have supported expectations that hand-harvested blocks would have yielded higher fruit. Numerous UF/IFAS field trials, however, have found no evidence that mechanical harvesting equipment adversely affects fruit yield or long-term tree health.

Since mechanical harvesters recovered, on average, 80 percent of the initial fruit, available yield for hand harvesters 
was significantly different between hand-harvested and machine-harvested blocks. When combined with handharvested blocks, available yield data ranged from 25 to 722 boxes per acre. Differences in worker productivity were also significantly different between hand-harvested and machine-harvested blocks. Worker productivity for the 38 hand-picked blocks averaged 9.44 boxes per hour (Table 1). Worker productivity to glean behind the 74 mechanically picked blocks averaged 6.35 boxes per hour. A more extensive discussion of the data collected for this study can be found in Roka and Hyman (2013).

The scatter plot of data points on worker productivity and corresponding available yield (Figure 2 ) suggests a logarithmic relationship between worker productivity and available yield. Transforming adjusted yield values to natural logarithms allows a linear model to be estimated as $\mathrm{L}_{\mathrm{p}}=1.53002 *\left(\ln \left(\mathrm{Y}_{\mathrm{a}}+1\right)\right)$, where $\mathrm{L}_{\mathrm{p}}$ is labor productivity (boxes per hour) and $\mathrm{Y}_{\mathrm{a}}$ is available yield (boxes per acre) to be hand harvested. The estimated parameter for the transformed value of available yield (1.53002) was positive and significantly different from zero. More than 93 percent of the change in worker productivity was explained by the model.

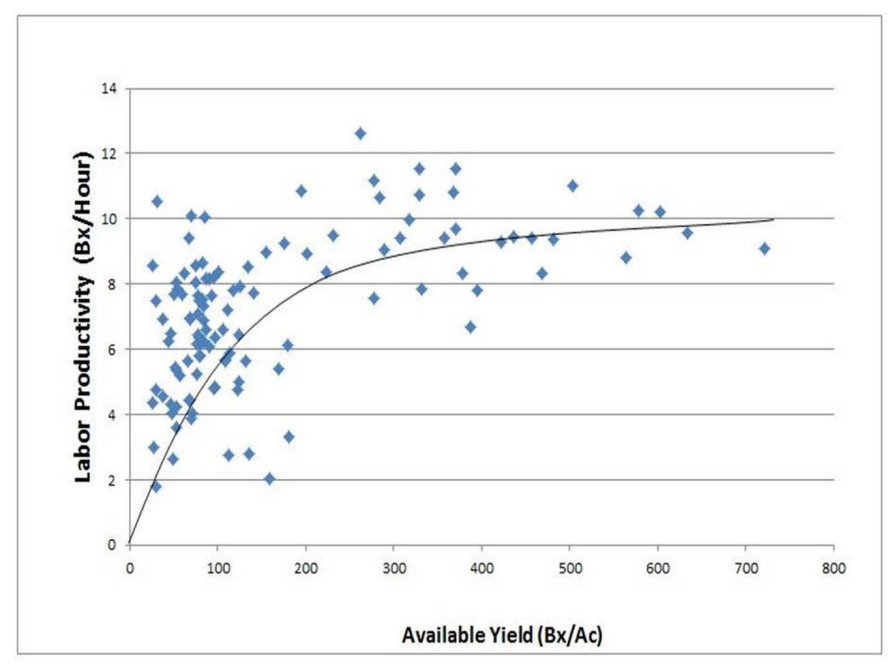

Figure 2. Scatter plot of data points showing available yield (bx/acre) along $\mathrm{X}$-axis and worker productivity (bx/hr) along Y-axis.

\section{The Value of Machinery Improvements: Implications for Harvest Costs}

Piece rates, roadside charges, and total harvesting costs are all dependent on predicted values of labor productivity.

Table 2 presents predicted labor productivity $\left(\mathrm{L}_{\mathrm{p}}\right)$ rates as a function of available yield $\left(\mathrm{Y}_{\mathrm{a}}\right)$ for a hypothetical block producing 400 boxes per acre. This yield target is slightly more than statewide averages for both Hamlin and Valencia oranges, reflecting an above-average grower considering mechanical harvesting. As the recovery percentage of mechanical harvesting increases to 95 percent, available fruit for hand labor (i.e., gleaners) decreases to 20 boxes per acre. Productivity of hand labor is estimated to decrease from more than 9.17 boxes per hour for complete handharvesting to 4.66 boxes per hour for workers following a mechanical system recovering 95 percent of the total crop. Given an hourly wage goal of $\$ 8.00$, the projected piece rates for hand/gleaning harvest increases from $\$ 0.87$ per box for hand harvesters to $\$ 1.72$ per box for gleaners.

Roadside charges increase with piece rates, but not on a one-to-one basis. The roadside charges listed in Table 2 were based on cost information provided by the labor contractors who cooperated with this study. At a pick-piece rate of $\$ 0.70$ per box, both contractors charged $\$ 0.70$ per box for roadside fruit. When the piece rate rose to $\$ 1.50$, their roadside rates increased to $\$ 1.40$ per box. Haul costs were independent of available yield and worker productivity and, for this example, were assumed to be $\$ 0.75$ per box. Total harvest costs, which are the sum of pick, roadside, and haul rates, were predicted to increase from $\$ 2.44$ to $\$ 3.88$ per box as available fruit for hand harvesting decreased from 400 to 20 boxes per acre.

Projected piece rates and total harvest costs can be estimated for any hourly earnings target. As the case in point, harvesting companies that recruit foreign guest workers through the $\mathrm{H}-2 \mathrm{~A}$ program have to pay at least the adverse effect wage rate (AEWR). The AEWR as of January 1, 2013, was $\$ 9.97$ per hour. Based on the assumption that $\mathrm{H}-2 \mathrm{~A}$ and domestic workers are equally productive, the projected piece rate to hand harvest 400 boxes per acre and to meet a target hourly earnings of $\$ 10.00$ is $\$ 1.09$ per box (Table 3 ), or an increase of $\$ 0.22$ per box when the hourly target was $\$ 8.00$. As available yield decreases to 20 boxes per acre, the projected piece rate increases to $\$ 2.15$ per box, and total harvesting costs become $\$ 4.61$ per box (Table 3).

The break-even harvest price is the minimum fruit price a grower needs to receive before harvesting and delivering fruit to a processing plant. Florida citrus growers are paid on the basis of pound solids (p.s.) of sugar content, and between the years 2000 and 2008, sweet oranges averaged 6.235 pounds solids per box (FASS 2009). Dividing total harvesting costs ( $\$ /$ box) by the number of pound solids per box provides a break-even fruit price above which it is economical to glean. When the targeted hourly earnings is $\$ 8.00$ and only 5 percent of the available crop remains to be 
gleaned by manual labor, the break-even price for gleaning harvest is $\$ 0.62$ per pound solids (Table 2 ). If the hourly earnings target increases to $\$ 10.00$, the break-even price to glean the same amount of fruit increases to $\$ 0.74$ per pound solids (Table 3 ). So long as a grower's delivered-in or FOB price at the processing plant exceeds the break-even harvest price, gleaning fruit after mechanical harvesting is a financially sound decision. Since 2004, growers have been paid more than $\$ 1.00$ per pound solids (FASS 2009). Even if mechanical equipment were to collect 99 percent of the available fruit, the high fruit prices and predicted productivity of gleaning labor suggests that gleaning will likely remain an integral part of any mechanical harvesting system.

\section{Concluding Remarks}

Mechanical harvesting technology has the potential to significantly reduce harvest costs for Florida citrus growers (Brown 2002). Given the global competition that exists within the orange juice market and higher production costs incurred from combating diseases such as citrus greening, the economic opportunities afforded by mechanical harvesting are increasingly important to the Florida citrus industry.

The ability of existing mechanical harvesters (i.e., CCSC systems) to recover fruit ranges widely from 70 to 95 percent of the available crop. While grove conditions can be modified and machine designs improved to increase fruit recovery percentages, mechanical systems will never equal the fruit recovery percentages from hand-harvesting crews, much less capture 100 percent of the available fruit. Whether or not to glean (to use manual labor to collect fruit not harvested by the machine) will remain an important question that growers will have to face with every block they choose to mechanically harvest.

This study incorporated field harvesting data and developed a model that predicted the extent to which labor productivity would be affected by decreasing the number of oranges available for harvesting by manual labor. Three conclusions can be reached from this study:

1. As available yield declines, average worker productivity decreases.

2. Lower average worker productivity implies that unit harvest costs, which include piece rates and roadside charges, will have to increase to maintain a constant level of hourly earnings for citrus harvest workers and their crew leaders.
3. Given current market prices of fruit, recovery percentage of crops harvested using mechanical harvesting equipment can improve up to 99 percent and gleaning will remain a profitable activity.

\section{References}

Brown, G.K. 2002. Mechanical harvesting systems for the Florida citrus juice industry. ASAE Paper 021108. Proceedings of the America Society of Agricultural Engineers, St. Joseph, MI.

FASS. 2009. Citrus Summary 2007-08. United States Department of Agriculture, National Agricultural Statistics Service, Florida Agricultural Statistics Service, Orlando FL. http://www.nass.usda.gov/Statistics_by_State/Florida/ Publications/Citrus/cs/2007-08/cs0708all.pdf

Muraro, R.P. 2009. Southwest Florida and Central Florida Summary Budget Costs 2007-2008. University of Florida, Citrus Research and Extension Center, Lake Alfred, FL. http://www.crec.ifas.ufl.edu/extension/economics/

Roka, F.M., and B.R. Hyman. 2013. Gleaner productivity, implied piece rates, and implications for citrus mechanical harvesting. Proceedings of the Florida State Horticultural Society 125 (forthcoming).

Roka, F.M. and B.R. Hyman. 2004. Evaluating Performance of Citrus Mechanical Harvesting Systems, 2003/04. Report to the Citrus Harvesting Research Advisory Council, Lakeland, FL (August). 
Table 1. Summary statistics of study blocks by harvest method. A different letter indicates that average values corresponding to harvest method (Hand and Machine/Glean) are significantly different.

\begin{tabular}{|lccc|}
\hline & & Hand & Machine/Glean \\
\hline Number of blocks & $(\mathrm{n})$ & 38 & 74 \\
\hline Average yield & $(\mathrm{bx} / \mathrm{ac})$ & $357.3(\mathrm{a})$ & $391.5(\mathrm{a})$ \\
Range (min-max) & & $(62-722)$ & $(181-792)$ \\
\hline Available yield & $(\mathrm{bx} / \mathrm{ac})$ & $357.3(\mathrm{a})$ & $78.3(\mathrm{~b})$ \\
Range (min-max) & & $(62-722)$ & $(25-169)$ \\
\hline Worker productivity & $(\mathrm{bx} / \mathrm{hr})$ & $9.44(\mathrm{a}))^{1}$ & $6.35(\mathrm{~b})$ \\
Range (min-max) & & $(3.3-16.4)$ & $(2.6-10.5)$ \\
\hline
\end{tabular}

Table 2. Predicted hourly worker productivity $\left(\mathrm{L}_{\mathrm{p}}\right)$, harvesting piece rates, total harvest costs, and break-even price based on available yield $\left(\mathrm{Y}_{\mathrm{A}}\right)$ after mechanical harvesting $(\mathrm{MH})$ and target hourly earnings of $\$ 8.00$ per hour. Production assumed to be 400 boxes per acre and 6.235 pound solids (p.s.) per box.

\begin{tabular}{|c|c|c|c|c|c|c|}
\hline MH Recovery & $\begin{array}{c}\text { Available Yield } \\
\mathbf{Y}_{\mathrm{A}} \\
\text { (bx/ac) }\end{array}$ & $\begin{array}{c}\text { Predicted Labor } \\
\text { Productivity }^{1} \\
\mathbf{L}_{\mathrm{p}} \\
(\mathrm{bx} / \mathrm{hr})\end{array}$ & $\begin{array}{c}\text { Projected Piece } \\
\text { Rate: } \\
\$ 8.00 / \mathrm{hr} \text { target } \\
(\$ / \mathrm{bx})\end{array}$ & 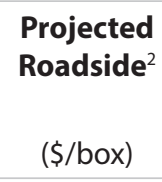 & $\begin{array}{c}\text { Total Harvest } \\
\text { Cost }^{3} \\
(\$ / b x)\end{array}$ & Break-even Price \\
\hline $99 \%$ & 4 & 2.46 & 3.25 & 2.48 & 6.48 & 1.04 \\
\hline $95 \%$ & 20 & 4.66 & 1.72 & 1.41 & 3.88 & 0.62 \\
\hline $90 \%$ & 40 & 5.68 & 1.41 & 1.20 & 3.35 & 0.54 \\
\hline $85 \%$ & 60 & 6.29 & 1.27 & 1.10 & 3.12 & 0.50 \\
\hline $80 \%$ & 80 & 6.72 & 1.19 & 1.04 & 2.98 & 0.48 \\
\hline $75 \%$ & 100 & 7.06 & 1.13 & 1.00 & 2.89 & 0.46 \\
\hline $70 \%$ & 120 & 7.34 & 1.09 & 0.97 & 2.81 & 0.45 \\
\hline $65 \%$ & 140 & 7.57 & 1.06 & 0.95 & 2.76 & 0.44 \\
\hline $60 \%$ & 160 & 7.77 & 1.03 & 0.93 & 2.71 & 0.43 \\
\hline $55 \%$ & 180 & 7.95 & 1.01 & 0.91 & 2.67 & 0.43 \\
\hline $50 \%$ & 200 & 8.11 & 0.99 & 0.90 & 2.64 & 0.42 \\
\hline $45 \%$ & 220 & 8.26 & 0.97 & 0.89 & 2.61 & 0.42 \\
\hline $40 \%$ & 240 & 8.39 & 0.95 & 0.88 & 2.58 & 0.41 \\
\hline $35 \%$ & 260 & 8.51 & 0.94 & 0.87 & 2.56 & 0.41 \\
\hline $30 \%$ & 280 & 8.63 & 0.93 & 0.86 & 2.54 & 0.41 \\
\hline $25 \%$ & 300 & 8.73 & 0.92 & 0.85 & 2.52 & 0.40 \\
\hline $20 \%$ & 320 & 8.83 & 0.91 & 0.84 & 2.50 & 0.40 \\
\hline $15 \%$ & 340 & 8.92 & 0.90 & 0.84 & 2.48 & 0.40 \\
\hline $10 \%$ & 360 & 9.01 & 0.89 & 0.83 & 2.47 & 0.40 \\
\hline $5 \%$ & 380 & 9.09 & 0.88 & 0.83 & 2.46 & 0.39 \\
\hline $0 \%$ & 400 & 9.17 & 0.87 & 0.82 & 2.44 & 0.39 \\
\hline \multicolumn{7}{|c|}{$\begin{array}{l}\text { Notes: } \\
1 \text { Labor Productivity Model: } L_{p}=1.53002 \times\left(\ln \left(Y_{A}+1\right)\right) \\
{ }^{2} \text { Roadside charge estimated by linear formula based on employer data for roadside rates at two different piece rates: } \$ 0.70 @ \$ 0.70 \text { piece rate } \\
\text { and } \$ 1.40 @ \$ 1.50 \text { piece rate. } \\
{ }^{3} \mathrm{Haul} \text { cost: } \$ 0.75 \text { per box. } \\
{ }^{4} 6.235 \text { p.s./box }\end{array}$} \\
\hline
\end{tabular}


Table 3. Predicted hourly worker productivity $\left(\mathrm{L}_{\mathrm{p}}\right)$, harvesting piece rates, total harvest costs, and break-even price based on available yield $\left(\mathrm{Y}_{\mathrm{A}}\right)$ after mechanical harvesting $(\mathrm{MH})$ and target hourly earnings of $\$ 10.00$ per hour. Production assumed to be 400 boxes per acre and 6.235 pound solids (p.s.) per box.

\begin{tabular}{|c|c|c|c|c|c|c|}
\hline MH Recovery & $\begin{array}{c}\text { Available Yield } \\
\mathbf{Y}_{\mathrm{A}} \\
(\mathrm{b} / \mathrm{ac})\end{array}$ & $\begin{array}{c}\text { Predicted Labor } \\
\text { Productivity }^{1} \\
\mathbf{L}_{\mathrm{p}} \\
(\mathrm{bx} / \mathrm{hr})\end{array}$ & $\begin{array}{c}\text { Projected Piece } \\
\text { Rate: } \\
\$ 10.00 / \mathrm{hr} \text { target } \\
(\$ / \mathrm{bx})\end{array}$ & 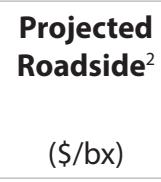 & $\begin{array}{c}\text { Total Harvest } \\
\text { Cost }^{3} \\
(\$ / b x)\end{array}$ & Break-even Price \\
\hline $99 \%$ & 4 & 2.46 & 4.06 & 3.05 & 7.86 & 1.26 \\
\hline $95 \%$ & 20 & 4.66 & 2.15 & 1.71 & 4.61 & 0.74 \\
\hline $90 \%$ & 40 & 5.68 & 1.76 & 1.44 & 3.95 & 0.63 \\
\hline $85 \%$ & 60 & 6.29 & 1.59 & 1.32 & 3.66 & 0.59 \\
\hline $80 \%$ & 80 & 6.72 & 1.49 & 1.25 & 3.49 & 0.56 \\
\hline $75 \%$ & 100 & 7.06 & 1.42 & 1.20 & 3.37 & 0.54 \\
\hline $70 \%$ & 120 & 7.34 & 1.36 & 1.16 & 3.28 & 0.53 \\
\hline $65 \%$ & 140 & 7.57 & 1.32 & 1.13 & 3.21 & 0.51 \\
\hline $60 \%$ & 160 & 7.77 & 1.29 & 1.11 & 3.15 & 0.50 \\
\hline $55 \%$ & 180 & 7.95 & 1.26 & 1.09 & 3.10 & 0.50 \\
\hline $50 \%$ & 200 & 8.11 & 1.23 & 1.07 & 3.06 & 0.49 \\
\hline $45 \%$ & 220 & 8.26 & 1.21 & 1.06 & 3.02 & 0.48 \\
\hline $40 \%$ & 240 & 8.39 & 1.19 & 1.04 & 2.99 & 0.48 \\
\hline $35 \%$ & 260 & 8.51 & 1.17 & 1.03 & 2.96 & 0.47 \\
\hline $30 \%$ & 280 & 8.63 & 1.16 & 1.02 & 2.93 & 0.47 \\
\hline $25 \%$ & 300 & 8.73 & 1.15 & 1.01 & 2.91 & 0.47 \\
\hline $20 \%$ & 320 & 8.83 & 1.13 & 1.00 & 2.89 & 0.46 \\
\hline $15 \%$ & 340 & 8.92 & 1.12 & 0.99 & 2.87 & 0.46 \\
\hline $10 \%$ & 360 & 9.01 & 1.11 & 0.99 & 2.85 & 0.46 \\
\hline $5 \%$ & 380 & 9.09 & 1.10 & 0.98 & 2.83 & 0.45 \\
\hline $0 \%$ & 400 & 9.17 & 1.09 & 0.97 & 2.81 & 0.45 \\
\hline \multicolumn{7}{|c|}{$\begin{array}{l}\text { Notes: } \\
{ }^{1} \text { Labor Productivity Model: } L_{p}=1.53002 \times\left(\ln \left(Y_{A}+1\right)\right) \\
{ }^{2} \text { Roadside charge estimated by linear formula based on employer data for roadside rates at two different piece rates: } \$ 0.70 @ \$ 0.70 \text { piece rate } \\
\text { and } \$ 1.40 @ \$ 1.50 \text { piece rate. } \\
{ }^{3} \mathrm{Haul} \text { cost: } \$ 0.75 \text { per box. } \\
{ }^{4} 6.235 \text { p.s./box }\end{array}$} \\
\hline
\end{tabular}

